\title{
Collaboration in mitigating spatial and skills mismatch: Exploring shared understandings between transit planners and workforce professionals
}

\author{
Andrew Guthrie \\ University of Minnesota-Twin Cities \\ guth0064@umn.edu \\ Yingling Fan (Corresponding Author) \\ University of Minnesota-Twin Cities \\ yingling@umn.edu
}

\author{
Fernando Burga \\ University of Minnesota-Twin Cities \\ hfburga@umn.edu
}

\begin{abstract}
Transit-dependent workers frequently find themselves caught between spatial mismatch (a lack of transportation options to reach jobs one is qualified for) and skills mismatch (a lack of needed qualifications for jobs one can reach). Historically, policy responses to these twin problems have essentially been siloed, with some responses focused on improving disadvantaged workers' mobility and others on skills training. Using the Twin Cities as an example of a healthy regional economy with areas of persistent disadvantage, this paper addresses the following research question: How do transit planners and workforce development professionals perceive the issues of spatial and skills mismatch and collaboration? This analysis explores this question through in-depth interviews with 16 transit planners and workforce development providers involved with one or more of seven study areas. The authors create an explanatory typology of areas to address with integrated transit planning and workforce development, interpret informants' intersubjective understandings of the state of efforts, and apply Innes and Booher's Diversity-Interdependence-Authentic Dialogue (DIAD) model of collaborative rationality to explore opportunities for deepening collaboration. The paper concludes with policy recommendations to connect marginalized workers with broader opportunities through transit planning and workforce development collaboration.
\end{abstract}

Keywords: transit, workforce development, planning, collaboration, coordination, spatial mismatch, skills mismatch

\section{Introduction}

Transit-dependent workers frequently find themselves caught between spatial mismatch (a lack of transportation options to reach jobs one is qualified for) and skills mismatch (a lack of needed qualifications

Copyright 2018 Andy Guthrie, Fernando Burga \& Yingling Fan

http://dx.doi.org/10.5198/jtlu.2018.985

ISSN: 1938-7849 | Licensed under the Creative Commons Attribution - Noncommercial License 4.0

The Journal of Transport and Land Use is the official journal of the World Society for Transport and Land Use (WSTLUR) and is published and sponsored by the University of Minnesota Center for Transportation Studies. This paper is also published with additional sponsorship from WSTLUR. 
for jobs one can reach). The issues of spatial and skills mismatch are two of the most prevalent labor market explanations of long-term unemployment (Fan, 2012; Houston, 2005). Spatial mismatch highlights the lack of job opportunities within the commuting and job search spheres of the unemployed (Gobillon, Selod, \& Zenou, 2007). The spatial mismatch hypothesis was first proposed by John F. Kain in the 1960s as an explanation for persistent, intergenerational poverty among inner-city African Americans (Kain, 1968). In its original form, the hypothesis proposed that a combination of housing discrimination, employment suburbanization, and low rates of automobile ownership trapped poor Black people in segregated, inner city neighborhoods far from entry-level employment opportunities with no way to reach them (Kain, 1968). Since its initial proposal, the focus of the spatial mismatch hypothesis has broadened to include a wide variety of intersecting identities among the urban poor, including immigrants, Latinos, single mothers, welfare recipients, and others (Fan, 2012).

The underlying concept of a mismatch between the circumstances of disadvantaged workers has proven useful for understanding long-term unemployment from other perspectives as well. One particularly important perspective is skills mismatch. Skills mismatch highlights a mismatch between the skills of the unemployed and the skills demanded by employers (Haughton, 1990; Kasarda, 1990; Skinner, 2001). Research broadly comparing job proximity and skills mismatch, as well as poverty deconcentration, local economic development, mobility promotion, and workforce development has found skills mismatch to be a stronger predictor of employment outcomes than spatial mismatch (Chapple, 2009; Immergluck, 1998). Houston (2005), however, finds both skills mismatch and spatial mismatch to be significant, but argues that skills mismatch alone ignores system inequalities that stretch far beyond individual workers.

As regional economies improve throughout much of the nation, persistent areas of disadvantage weaken the success of the recovery, and race and class disparities interfere with the basic American ideal of equitable rewards for work. These disparities are most apparent and arguably deplorable in regions where the overall economy is strong, with specific groups left out (Chetty, Hendren, Kline, \& Saez, 2014; Corak, 2013). An extreme example of such a region is the Twin Cities of Minneapolis-Saint Paul, Minnesota. While the region as a whole has an exceptionally low unemployment rate, its Black-White income and wealth disparities are among the highest in the United States (U.S. Census Bureau, 2016a; U.S. Census Bureau, 2016b). In fact, recent data from the Minnesota Department of Employment and Economic Development show that Twin Cities job vacancies roughly equal the number of Twin Cities residents looking for work (Department of Employment and Economic Development, 2016; O'Niel, 2016). Persistent unemployment, underemployment, and poverty among marginalized residents betrays a policy failure in connecting disadvantaged workers with job opportunities either literally (in terms of transportation) or figuratively (in terms of skills training). Greater collaboration between service providers is easy to call for, but how can it actually be accomplished in the messy world of urban and regional policy and planning? This leads us to the research question: How do transit planners and workforce development professionals perceive the issues of spatial/skills mismatch and collaboration?

Conventional wisdom among policymakers has led to separate efforts addressing these two issues (Handel, 2003; McQuaid, 2006). Efforts to mitigate spatial mismatch often include spatially targeted poverty dispersal and job creation as well as transportation improvements for the poor (Fan, 2012; Fan et al., 2012), while efforts to mitigate skills mismatch tend to focus on skill-building and occupational training programs for low-income job seekers (Giloth, 2000).

Siloed efforts to address spatial and skills mismatch have met with limited success. Planners' efforts focused on spatial mismatch frequently prove ineffective, politically unfeasible or both (Fan, 2012). While workforce development efforts focused on skills mismatch can help individual workers, intergenerational poverty persists among marginalized communities (Turner, Edelman, Poethig, \& Aron, 2014). 
Recently, a handful of cities and regions have seen cross-sectoral efforts that simultaneously mitigate spatial and skills mismatch. These efforts often occur in metropolitan regions with ambitious investments in new rail and bus services. For example, the Mile High Connects Job Access Initiative in the Denver, Colorado region has led regional stakeholders to incorporate economic and workforce development into light rail station areas and neighborhood plans (Mile High Connects, 2016). The initiative also calls for outreach programs to employers, workforce training providers, and other supportive service providers about the benefits of transit. The Corridors 2 Careers project in the Minneapolis-St. Paul, Minnesota region aligns employment needs of existing and emerging businesses along the Metro Green Line light rail corridor with skills assessment, training, and employment services provided to corridor residents (District Councils Collaborative, 2014).

Although these cross-sectoral efforts have pointed to new opportunities for integrated transit and workforce development, they tend to target specific transit corridor areas and are not systems level solutions for mitigating spatial and skills mismatch in a region. This situation exists despite an understanding in existing research that spatial and skills mismatch are metropolitan region-level problems (Bauder \& Perle, 1999; Houston, 2005; Stoll, 2005). In addition, planners and workforce development professionals frequently seek to advance different organizational goals that may foster but also work against collaboration given the specific cases. The challenge confronting corridor focused solutions versus metropolitan scale issues calls for the deployment of theoretical frameworks that provide inductive understandings about how collaboration may be harnessed in this space of complexity.

The concept of collaborative rationality offers a relevant lens to analyze a collaborative transit planning/workforce development response (Booher \& Innes, 2002). Booher and Innes (2002) articulate a theory of collaborative rationality based on diversity of interests, interdependence of interests, and authentic dialogue between participants—also known as the DIAD model. By using the DIAD model to interpret the interviews collected for this study, we find that transit planners and workforce development professionals portray differing mixes of interests concerning diversity, that they have complementary goals concerning interdependence of interests, and that they lack authentic dialogue to achieve a desirable degree of collaboration. By applying the DIAD model to the Twin Cities case we can understand the tensions that arise when coordination among multiple actors takes place and consider what aspects may establish or strengthen collaboration towards this goal. The DIAD model is particularly appropriate for the interpretation of joint efforts addressing spatial and skills mismatch because its concepts do not focus on a formal, coordinating organization. Rather, the collaborative rationality approach it theorizes can be understood as a complex, adaptive system formed of organizations and stakeholders with horizontal—as opposed to hierarchical—relationships to each other (Innes \& Booher, 2010).

There has been an extensive quantitative literature (Blumenberg \& Manville, 2004; Chapple, 2006; Grengs, 2010) considering the effectiveness of planning interventions in alleviating spatial mismatch and that of workforce development efforts in alleviating skills mismatch. However, there is little scholarly research to date directly considering the tensions, meanings, and values that arise between practitioners when efforts are carried out to foster collaboration between the two. As such collaboration hinges on actions by individuals in disparate organizations with disparate goals, the human interactions that constitute it and the meanings participants ascribe to them are of great interest because they not only define how practitioners place value in their practice but also how institutions ascribe goals and objectives in strategic planning and mission statements. Closing this research gap calls for a qualitative approach focused on the development of case studies and interviews to address those interactions and meanings.

This paper describes the authors' exploration of the research question and its components through semi-structured interviews with eight transit planners, seven workforce development providers, and one 
public official in the Twin Cities region in Minnesota. Interviewees were recruited from seven areas of the region, including areas with plentiful affordable housing but few entry level jobs, areas with little affordable housing but plentiful entry level jobs, and areas with poor transit services, good transit services, and currently poor services with planned improvements. We apply Innes and Booher's (2010) DIAD (Diversity of interests, Interdependence of interests, Authentic Dialogue) as an ideal model of collaborative rationality to interpret the tensions, values, and meanings that transit and workforce practitioners perceive in coordinating their work, and to identify opportunities for deepening that coordination. This interpretation informs future policy recommendations to produce effective, collaborative action between transit and workforce practitioners in connecting marginalized workers with broader opportunities.

\section{Approach}

Jointly addressing spatial and skills mismatch through coordination between workforce development programs and transit planning will require collaboration between people working in different agencies with different service goals. Advancing that collaboration calls for understanding how professionals in both fields define the problems of spatial and skills mismatch, and understanding the intersubjective, shared meanings they ascribe to those problems when they impact their work. The coordination needed to achieve pre-established goals presents an entry point for the work of developing shared meanings through collaborative action.

To that end, the authors employed semi-structured interviews with 16 transit planners and workforce development professionals in the Twin Cities region of Minneapolis-Saint Paul, Minnesota. The interviews specifically considered how transit planners and workforce development professionals conceive the challenges and opportunities they face in achieving collaboration.

\subsection{Selection of study areas and interviewees}

In order to acquire an sample across the twin cities region, we select study areas to maximize contrasts, both in terms of specific issues of spatial and skills mismatch, but also in terms of prosperity and disadvantage. Interviewees were recruited based on their involvement with the selected study areas. Table 1 presents a selection matrix used to determine study areas. The matrix places the areas in which our interviewees work into an explanatory typology based on how their circumstances relate to the twin problems of spatial and skills mismatch. The rows in the table show areas with either an ample supply of suitable jobs for disadvantaged workers and limited affordable housing, or areas with few suitable jobs and plentiful affordable housing. The latter are important as areas where workers to be served are likely to live (their commute origins), and the former as areas they are likely to work (their commute destinations). Columns show transit service levels.

Table 1: Area selection matrix

\begin{tabular}{l|l|c|c|c}
\hline \multicolumn{2}{c}{} & \multicolumn{3}{c}{ Transit Services } \\
\cline { 3 - 5 } \multicolumn{2}{c|}{} & Poor & $\begin{array}{c}\text { Poor now, planned } \\
\text { improvements }\end{array}$ & Good \\
\hline \multirow{3}{*}{$\begin{array}{l}\text { Extent of spatial and } \\
\text { skills mismatch }\end{array}$} & $\begin{array}{l}\text { Ample jobs, limited affordable } \\
\text { housing nearby }\end{array}$ & Shakopee & $\begin{array}{c}\text { Golden Triangle/ } \\
\text { Gateway }\end{array}$ & Mall of America \\
\cline { 2 - 5 } & $\begin{array}{l}\text { Ample affordable housing, limited } \\
\text { suitable jobs nearby }\end{array}$ & N/A & $\begin{array}{c}\text { North Mpls/ } \\
\text { Brooklyn Park }\end{array}$ & Phillips \\
\hline
\end{tabular}

As shown in Table 1, we selected areas primarily on the principle of maximizing variation of service and mismatch. We included two areas for each cell in the "Poor now, planned improvements" column 
due to special interest in major transit projects that offer regular, all-day services. All-day frequent transit services are especially important for disadvantaged workers due to often complex travel patterns and family obligations. Two areas (Phillips and the Mall of America area) are served by existing light rail transit (LRT) and/or bus rapid transit (BRT) lines. Shakopee has extremely limited bus services, oriented primarily to park-and-ride commuters bound for downtown Minneapolis. The remaining areas have varying degrees of existing bus services, as well as planned LRT, BRT, and/or rapid bus services.

The matrix has been compressed using Elman's procedure of eliminating absent and/or irrelevant rows, columns, and cells (Elman, 2005). For example, regionally important concentrations of affordable housing invariably have at least a moderate level of transit services, as they are excellent markets for transit. Also, while areas with low unemployment and few nearby jobs certainly exist in the region, they are uninteresting to this research as they neither represent disadvantaged populations to be employed, nor jobs to employ them in. In addition, because transit service levels, affordable housing concentrations and job concentrations covary, the relationship between columns is consistent within rows but not necessarily between rows (and vice-versa). For example, North Minneapolis and Brooklyn Park both currently have better transit service than Golden Triangle and the Gateway corridor, but North Minneapolis and Brooklyn Park currently have worse service than Phillips, while Golden Triangle and Gateway currently have worse service than the Mall of America area.

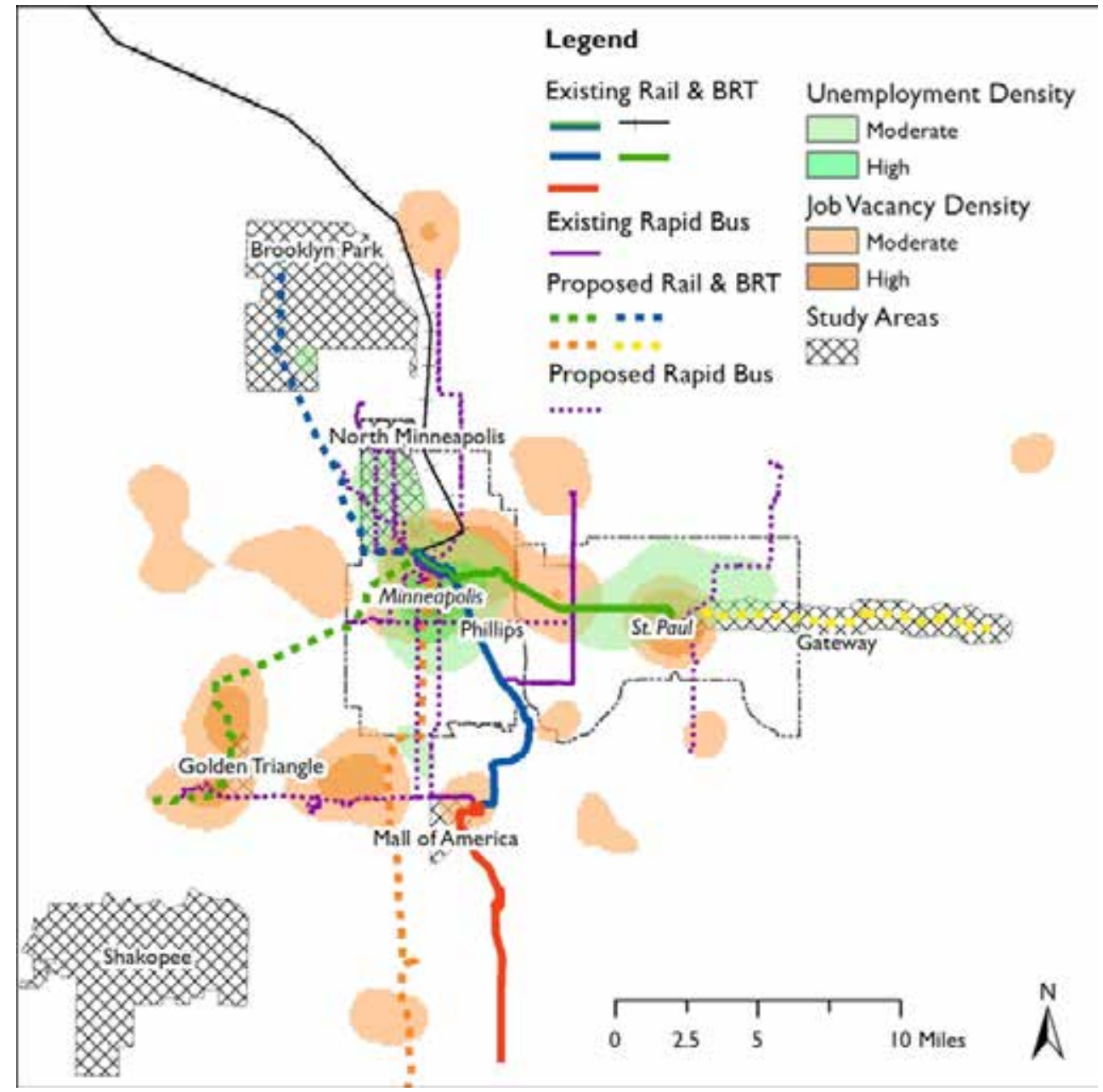

Figure 1: Study areas, spatial mismatch, and the transit system 
Figure 1 shows the study locations in the seven county Twin Cities metropolitan region in the context of concentrations of unemployment and job vacancies as well as the current and proposed regional transitway system. Figure 1 also illustrates the spatial mismatch issues facing the region: while significant concentrations of job vacancies exist in the transit-served inner metro, transit-dependent workers are essentially excluded from most suburban employment opportunities. It is worth noting that we focus on specific areas within the region, not for their own sakes, but to explore the issues of spatial and skills mismatch at maximum intensity. This study can be seen as exploring a least-likely case: solutions that are viable in our context should transfer with relative ease to less intense ones. Although we did not specifically attempt to maximize the spread of study areas throughout the metro area, fulfilling the typology created by the selection matrix (shown in Table 1) largely accomplished that without much need for our intervention. Areas studied include urban neighborhoods (North Minneapolis and Phillips), inner suburbs (Mall of America and Brooklyn Park) and outer suburbs (Golden Triangle and Shakopee). The Gateway Corridor includes urban neighborhoods, and inner and outer suburbs.

We then recruited at least one transit planner and workforce development professional at the senior staff level with responsibility for and/or direct working knowledge of each area of interest. The correspondence is not necessarily one-to-one. For example, as Metro Transit is a regional agency, the seven Metro Transit staff interviewed provided information at the regional level. Workforce development professionals have more direct local connections due to a county-based structure of workforce development programs in Minnesota. Table 2 shows the positions held by interviewees and the organizations they work with.

Table 2: Positions and organizations of interview participants

\begin{tabular}{ll|lc}
\hline Positions & Organizations & \\
\hline Workforce Development Professionals & 4 & Local/State Government & 7 \\
Workforce \& Economic Development Professionals & 3 & Transit Agency & 7 \\
Transit Planners & 8 & Private/Non-Profit Sector & 2 \\
Elected Officials & 1 & & \\
\hline Total & 16 & Total & 16 \\
\hline
\end{tabular}

The authors interviewed eight transit planners, seven workforce development professionals, and one public official. The specific geographic focus of the study, as well as the focus on senior and executive level staff allowed us to approach saturation in terms of interviewing as many individuals meeting our selection criteria who were willing to participate.

\section{$2.2 \quad$ Interviews}

The interviews were semi-structured, lasting from 30 minutes to over an hour, with interviewees largely allowed to define the conversation. While interviewers worked from prepared questions, these were not rigidly followed. The questions were used primarily to start conversations and ensure all needed topics were covered. Broadly, interviews with transit planners opened with a general question about what interviewees saw as important barriers to connecting disadvantaged workers with jobs via transit. Interviewees were then asked about how they expected proposed transit improvements to change those barriers, as well as any new challenges they saw arising as proposed lines were implemented. When needed, the interviewer would probe regarding the importance of the first-mile/last-mile problem in raising barriers to transit employment access for disadvantaged workers as well as attempts and potential strategies to alleviate them. Questions then shifted to collaboration with workforce development agencies, and asked 
what, if any, collaborative action is taking place, what transit agency goals it is seen as advancing and what results interviewers have seen, as well as what role interviewees saw for partnerships with employers to connect workers with transit service.

Interviews with workforce development professionals generally began by asking generally how their clients' access to transportation in general impacts the work they do, then, if necessary, follow up by asking directly about what role transit plays — whether for getting to work, to training programs, for reaching workforce centers themselves, or for other purposes. The interviewer would then ask specifically about the perceived adequacy of current transit service in the area, as well as the implications of any proposed transit improvements. Interviewees were then be asked if they collaborate with transit providers and/or planners, generally and-as appropriate—specifically in connection with proposed new transit corridors. For example, workforce development professionals in the Gateway Corridor were asked if and how they collaborate with the planning process for the Metro Gold Line-a BRT service slated to serve their area - to maximize the effectiveness of either or both parties' work, as well as how they approach collaboration in the context of a currently operating workforce development agency and a planned future transit service. Interviews concluded by asking interviewees if and how increased collaboration with transit planners might support their work, as well as what, if any, important conversations they believed were not taking place. As no formal, overarching regional program exists for coordinating the activities of transit planners and workforce development professionals, questions concerning collaboration focused on horizontal relationships between agencies and how those relationships relate to agency goals.

\subsection{Characteristics of study areas}

Table 3 shows basic demographic information for the study areas based on the 2014 American Community Survey. North Minneapolis and Phillips consistently stand out in measures of marginalized identities, with the sole exception of North Minneapolis-historically the heart of the Minneapolis African-American community - for foreign born residents.

Table 3 also shows current and future cumulative opportunity transit accessibility to job vacancies in each study area, weighted by population. The accessibility figures denote the number of jobs an average individual in each study area can reach in 45 minutes of travel by transit and/or walking during morning peak service. (Future accessibility assumes buildout of the proposed regional transit system slated for completion by 2040.) Both North Minneapolis and Phillips have relatively high transit accessibility and stand to see significant accessibility increases if the proposed regional transit system is implemented. However, the fact that both already have high accessibility and yet have high poverty rates supports the basic premise that transit improvements alone will be insufficient to functionally broaden access to opportunity in these areas and those like them.

Table 3: Demographics and transit accessibility by area

\begin{tabular}{|c|c|c|c|c|c|c|c|c|}
\hline Area & $\begin{array}{c}\text { Families } \\
<185 \% \\
\text { Poverty }\end{array}$ & $\begin{array}{c}\text { No } \\
\text { Postsecondary } \\
\text { Degree }\end{array}$ & $\begin{array}{c}\text { Non- } \\
\text { white } \\
\text { Residents }\end{array}$ & $\begin{array}{c}\text { Foreign } \\
\text { Born } \\
\text { Residents }\end{array}$ & $\begin{array}{c}\text { Single- } \\
\text { Parent } \\
\text { Families }\end{array}$ & $\begin{array}{c}\text { Current } \\
\text { Accessibility }\end{array}$ & $\begin{array}{c}\text { Future } \\
\text { Accessibility }\end{array}$ & $\begin{array}{l}\text { \% Change in } \\
\text { Accessibility }\end{array}$ \\
\hline Brooklyn Park & $20 \%$ & $59 \%$ & $39 \%$ & $17 \%$ & $13 \%$ & 1,365 & 1,677 & $23 \%$ \\
\hline Gateway Corridor & $24 \%$ & $55 \%$ & $38 \%$ & $15 \%$ & $12 \%$ & 1,270 & 1,489 & $17 \%$ \\
\hline Golden Triangle & $13 \%$ & $35 \%$ & $31 \%$ & $20 \%$ & $8 \%$ & 616 & 625 & $1 \%$ \\
\hline Mall of America & $26 \%$ & $65 \%$ & $39 \%$ & $18 \%$ & $13 \%$ & 2,930 & 3,364 & $15 \%$ \\
\hline North Minneapolis & $40 \%$ & $63 \%$ & $58 \%$ & $14 \%$ & $20 \%$ & 5,609 & 6,617 & $18 \%$ \\
\hline Phillips & $60 \%$ & $70 \%$ & $68 \%$ & $33 \%$ & $18 \%$ & 9,810 & 10,800 & $10 \%$ \\
\hline Shakopee & $10 \%$ & $46 \%$ & $22 \%$ & $12 \%$ & $7 \%$ & 78 & 78 & $0 \%$ \\
\hline
\end{tabular}


The following texts provide additional background information on the built form, regional location, and current and historical urban planning issues in each of the seven areas:

- Brooklyn Park is a northwest suburb of Minneapolis. Its southern parts are characteristic of older, mid-to-late 20th century suburban development, with rigidly segregated land uses, strip commercial and aging housing stock with signs of inner ring decline. However, they also provide a significant stock of affordable housing. Brooklyn Park is served primarily by local bus transit, with limited peak-only express service. Brooklyn Park is on the route of the planned Metro Blue Line Extension, which will offer light rail service to downtown Minneapolis and south-suburban employment centers.

- North Minneapolis (located north of downtown and west of the Mississippi River) is the traditional heart of the city's African American community, as well as some of the most deeply disadvantaged areas of the city. Although served by local bus routes, North Minneapolis has historically been bypassed by major transportation investments. Planned transit projects promise to change this: the Metro Blue Line extension will run along the south and west borders, and two proposed rapid bus lines will raise the quality of local service. One further corridor is in development as either streetcar or rapid bus. Despite its proximity to downtown Minneapolis, Northside traditionally suffers from both spatial and skills mismatch: many residents lack both transportation options to suburban jobs and qualifications for jobs downtown.

- The Phillips neighborhood in South Minneapolis is an area of diversity, history, and change. Traditionally home to one of the largest urban Native American communities in the nation, Phillips has recently seen an influx of Hispanic immigrants. The neighborhood is home to several major employers in the healthcare sector. While it has long been a prime example of skills mismatch, starting in 1997, it has benefitted from the Project for Pride in Living - an innovative partnership between major employers, workforce development service providers, and local government to prepare neighborhood residents for career-building jobs in the neighborhood. Along with a network of radial and cross-town local bus routes, Phillips is served by the Metro Blue Line LRT, and will be served by the Metro Orange Line BRT corridor.

- The Gateway Corridor along the proposed Metro Gold Line BRT stretches east from downtown Saint Paul most of the way to Wisconsin. On the way, it serves disadvantaged neighborhoods in East Side Saint Paul, several employment centers, and increasingly affluent suburbs. Surrounding built forms range from traditional in Saint Paul to increasingly automobile-oriented farther out. The corridor is almost a self-contained example of spatial mismatch, with few entry-level jobs near the Saint Paul neighborhoods it serves, and little affordable housing near its suburban employment centers.

- The Golden Triangle area in the southwest suburb of Eden Prairie-named for a triangle of major highways and a dense concentration of successful businesses-is a major employment center, with large numbers of entry-level and higher jobs. Golden Triangle has little affordable housing nearby, but will be served by the planned Metro Green Line extension. Though Golden Triangle should boast a light rail station by 2020 , it has an overwhelmingly automobileoriented built form.

- The Mall of America area in the inner suburb of Bloomington is a regional shopping destination and major center of retail employment. It is also a major regional transit hub, served by the Metro Blue Line, Metro Red Line and many bus routes. Currently featuring a very large-scale, automobile dominated built form with single-story office buildings and several vacant lots, the area immediately to the east of the mall is the center of a major transit-oriented redevelopment plan.

- Shakopee is an outer southwestern suburb, characterized by generally affluent housing as well as a nascent manufacturing and warehousing employment. With major new facilities and expansions planned in these sectors, Shakopee is less a current major employment center than po- 
tentially a future major employment center. In particular, a major Amazon regional fulfillment center as well as a large Shutterfly facility have recently added a large number of entry level jobs in an area with no transit service and very little affordable housing nearby. This situation makes it especially relevant from a planning standpoint, as expected future economic development will be significant enough to raise regional transit planning and workforce development issues.

\subsection{Analysis approach}

Working from full transcripts of all interviews, the authors employed word frequency analysis, topic coding, and close readings of transcripts to analyze participants' shared understandings of the current state of collaboration between transit and workforce development as well as opportunities for strengthening the collaboration. Word frequency analysis and topic coding do not allow for statistical analysis or generalization due to small sample size, among other reasons. They can, however, alert a researcher to recurring themes in interviews to be followed up through close, comparative readings of interview transcripts. In this case the development of themes provides findings about how transit planners and workforce development professionals perceive spatial and skills mismatch, and the need for collaboration to address them.

\section{$3 \quad$ General themes}

\subsection{Affordable housing in the region}

The spatial distribution of affordable housing can represent a challenge for disadvantaged workers if it leads to spatial mismatch. This is the sense in which affordable housing is mentioned most revealingly by participants: in and of itself, affordable housing (or a lack of it) is discussed most frequently regarding its spatial relationships to employment centers. Participants' perceptions of the affordable housing problem in the region focus heavily on the relative locations of affordable housing and employment opportunities suitable for its residents. While likely shaped by the study area selection process, the overwhelming understanding of spatial mismatch as a key affordable housing issue validates the underlying objective of this research, and underscores the importance of transportation in promoting social equity in the region.

Due to the lack of affordable housing nearby, discussion of the Golden Triangle employment center, for example, deals mainly with preparing disadvantaged workers from other areas for Golden Triangle jobs, especially considering increased access promised by LRT. Non-transportation barriers to employment, like child care access — especially in the context of long, regional commutes—are prominent. These issues were mentioned in our interviews primarily regarding the Golden Triangle area, but similar issues may arise in other areas and regions where regional employment distributions are dominated by single-use, suburban employment centers.

Discussion of transit planning in the Mall of America area often touched on a need to coordinate transit to the mall with affordable housing in the area-the mall itself already has exceptionally good transit for a suburban employment center. It is also important to note that the prevalence of retail employment minimizes skill mismatch where the Mall of America is concerned, as shown by this quote from a suburban workforce development professional:

Transit, I don't think it was a piece of it but the individual company would be talking to them, saying,

"This is where were at, this is what's available." It wasn't a conscious decision to promote that. Could it be? Sure, it could.

While areas with plentiful affordable housing generally come up in interviews as challenged by 
spatial mismatch, participants also understood some specific areas of affordable housing as assets for the access they offer to jobs in specific occupations. Examples include access to healthcare jobs in downtown Minneapolis and manufacturing jobs in the inner northwest suburbs from Brooklyn Park and North Minneapolis, as well as access to jobs as bus and heavy truck mechanics from North Minneapolis. Interestingly, both Metro Transit staff members and multiple workforce development professionals point to Metro Transit's large Heywood Garage as a promising opportunity to connect disadvantaged workers with jobs as either mechanics or drivers. Though arrived at independently, these shared general understandings indicate an opportunity for a high degree of collaboration, particularly due to the spatial and mobility focus of the workforce development professionals' comments and the employment and training focus of comments from Metro Transit staff. The following quote from a Minneapolis business leader with experience in community and workforce development illustrates the commonly-held perception that such areas offer untapped opportunities for connecting disadvantaged workers with jobs given better coordination in taking advantage of existing assets:

You can get mechanics at Heywood, healthcare at Hennepin County Medical Center. Well what about [training programs at] Metro State, or partnership [with] Hennepin County, and people in that neighborhood and it's all accessible via transit!

\subsection{Commute patterns and effective transit service}

Issues raised surrounding disadvantaged workers' commutes can be further divided into general issues dealing with particular commute patterns necessitated by regional spatial mismatch and specific challenges in providing effective transit service for those commute patterns. One of the more prominent general issues is a broadly shared understanding of the inadequacy of current transit offerings in suburban employment centers, as told by a suburban workforce development professional:

So we've used bus cards in the past when we, for people who live on a bus route-that helps-but how do you locate them, because this county's so long and narrow? We go from Forest Lake all the way down to Cottage Grove. So you're looking at those communities like Forest Lake, not a lot of transit service there! They may have a bus that runs from Forest Lake to Saint Paul, but there's no stops in between; it's an express service. Same here in Woodbury, it runs to [...] Minneapolis, but there's no stopping in between. So it gives us little relief. You know each community had tried all kinds of circulator services and stuff, but it just doesn't work, it works to a point but it takes so much resources for these services.

There is good reason for this pattern in the minds of transit planners, as illustrated by this quote from a transit agency executive:

When you're looking at the potential for transit connecting people to job centers, are you also looking at coordinating if the job centers locate in place that really these people could connect to more of these jobs? Because one of the challenges we face has been is that somebody locates a facility somewhere and then calls us up and wants transit, [...] and every transit agency across the country has had this challenge, and then: well the reason there isn't transit out there is a good reason. [...] [I]t's very rare for it to be possible to efficiently serve those locations with transit.

This understanding comes out in frequent discussion of the current difficulties workers face in relying on transit to reach Golden Triangle, as well as in discussion of the benefits (compared with current conditions) proposals to improve or begin transit service would have in Brooklyn Park and Shakopee, 
respectively. In the Gateway Corridor, there is a strong perception shared among transit planners and workforce development professionals that much of it would need to have transit service at all before coordinating that service with workforce development efforts would be a worthwhile endeavor.

\subsection{The first mile/last mile problem}

Not surprisingly, given the inclusion of several suburban employment centers as well as the decades-long trend of regional job sprawl, the first mile/last mile problem is consistently understood both as a central issue in connecting disadvantaged workers with jobs by transit and as one of the most difficult issues to address. It often arises in reference to suburban employment centers, but also comes up as a perceived obstacle transit-dependent urbanites face in using transit to reach jobs, even in residential areas with high levels of transit service. In these instances, a disadvantaged worker may have an easy time accessing transit from home, but face serious problems accessing a potential workplace from transit. There is a widely shared belief that conventional approaches to feeder service will be inadequate to serve a great variety of workplaces which are relatively near proposed transit stations, but outside of reasonable walking distance. This lack of confidence in the possibility of providing either effective fixed-route bus connections in many suburban employment centers or broadly effective dial-a-ride service leads both transit planners and workforce development professionals to express strong interest in unconventional, demand-responsive connecting services. This willingness to try anything, so to speak, is illustrated by the following quote from a transit planner interested in exploring roles for partnerships with ride-sharing companies, which could be subsidized based on need:

I think that's where the transportation networking companies, the Lyfts come in, because it's not a scheduled thing. [Transit riders] don't need to worry about that because it's not a scheduled thing. When somebody gets to the [suburban light rail] station, they call up and get a ride or they've got it prearranged, so boom! It doesn't matter whether [a] bus is running there or not, because they've got another option.

First mile/last mile issues arise in discussion of suburban residential areas, particularly along the Gateway Corridor, where much of the affordable housing that does exist is relatively near a planned BRT station, but not within walking distance. It is worth noting that the potential first mile-last mile solutions interviewees speculate about implicitly require coordination, whether between agencies, public and private sectors or both.

\subsection{Need for customized workforce development programs}

Participants frequently mentioned about the localized and clustered nature of certain types of job opportunities. Specifically, Golden Triangle is seen as an important center of back-office employment, while Phillips is seen as a center of healthcare employment, and the Gateway Corridor as a center of manufacturing employment. These geographic concentrations of opportunity are widely understood as calling for focused training programs offered to disadvantaged workers who have access to them. In parsing these perceptions, it is crucial to recognize that they are not exclusively based on empirical job data, but that they also incorporate workforce development professionals' and even transit planners' understandings of jobs that are both numerous and potentially available to disadvantaged, transit-dependent workers.

Further, workers' soft skills (arriving on time, dressing appropriately, getting along with supervisors and coworkers, etc.) are frequently discussed in low-income residential areas as an issue to address before specific job training or improved regional mobility become important. Soft skills are also understood 
to some extent, however, as an issue high-quality transit can help address by reducing the impact of a missed bus. Missing a train or bus on a route with 10-minute service frequency may result in a reprimand from a supervisor or even merely a scramble from station to workplace. For many entry-level jobs, missing a bus that only runs one to three times a day (as is often the case with special-purpose, reversecommute services) can leave workers out of a job.

In addition, participants pointed to some success stories of providing customized workforce development programs. In Phillips, where there are dense, high-frequency local transit services, workforce development professionals worked with nearby employers to develop training programs that focus on transit-accessible job opportunities. Another success involved convincing employers to systematically rethink their required qualifications for entry-level jobs and to support customized training. In doing so, employers in the healthcare sector were able to jettison barriers faced by disadvantaged workers.

They present their job description information and we see "you've got to have this, you've got to have that". No way! We want the employer to re-tool that. [...] Instead of having all these kind of [hiring] practices which just build up over the years, [we work with them] to support customized training.

\section{Themes about collaboration: Applying the DIAD model}

No overarching agency with the power to directly coordinate transit planning and workforce development exists in the Twin Cities region-a common situation throughout the United States and other countries. This situation leaves transit and workforce development agencies with related-though not identical—goals, yet formally independent structures and processes for advancing them. As such, any coordinated action between these two fields calls for collaboration across agency boundaries. Such collaboration exists in limited instances - surrounding planning for specific transit projects, for instancebut is not a regular feature in the region. Fostering such collaboration will require bridging transit planners' and workforce development professionals' understandings of the problems of spatial and skills mismatch, as well as their understandings of collaborative action to address them. The following section applies Innes and Booher's (2010) DIAD model to the interview results to interpret the tensions exemplifying the development of collaborative approaches dealing with the spatial/skills mismatch. Rather than deploying the DIAD model as a prescriptive framework to enable collaboration, this section explores its ideal concepts to theorize further actions and structures that may be needed to pursue transit planning and workforce development.

\subsection{Diversity: Differing mixes of multiple interests}

Based on the interviews, the first "D" in "DIAD" (Diversity of interests) is most certainly present. While transit agencies and workforce development agencies serve fundamentally different organizational goals, the interests represented by the statements made by interviewees emphasize a diversity of positions even within those two broad groups. In addition, various interviewees represent differing mixes of multiple key interests. Transit planners, not surprisingly, hope to increase transit use, as well as to improve the efficiency of routes, especially in suburban locales. Workforce development professionals aim to place their clients in jobs, as well as to start long-term unemployed individuals onto the first rung of a career ladder. Public officials aim to enhance regional quality of life and economic competitiveness - as well as to be reelected. These interests are related in some ways-for example: if a workforce development professional places a number of transit-dependent clients in entry-level, living-wage jobs served by a relatively unproductive suburban local transit route, those clients may begin to climb a career ladder while adding to transit use and improving the performance of the route in question. In turn, other clients (and the 
workforce development programs serving them), may also be able to realize savings on the automotive transportation that is a prerequisite of life in many suburban areas, even if accomplished by way of old, unreliable cars, as illustrated in this quote from a workforce development professional in the Gateway Corridor area:

I also think that it affects our programmatic budgets because [...] being that a car [...] is your only means of transportation in this area, when we have $x$ amount of budget specified for support service or services to help customers [with transportation], we're oftentimes spending large chunks on repairing older vehicles and having conversations with customers about whether their car is even worth repairing. And I think it can really take away from - because there's only $x$ amount allotted per person-so I think it could take away from supporting a customer for education or other family type support [...] which is disheartening sometimes.

This interviewee went on to agree that the ability to simply provide transit cards to clients could have significant positive impacts on their budget in other areas, enhancing their ability to help prepare clients for successful job searches. Those abilities, though, depend on improved transit mobility, as transit passes are of little use without service connecting clients' homes and destinations.

\subsection{Interdependence: No employment without transit, no ridership without workforce development}

While diverse, the interests represented in interviews meet the criterion of interdependence as well. The different actors who were interviewed recognized, for example, that workforce development professionals share an understanding of transit dependency as a significant constraint on placing clients in suitable jobs. This is exemplified in the following statement by an economic and workforce development professional with the City of Minneapolis:

When you are working in high poverty communities like we are talking about in North Minneapolis through the Northside job creation team, it is extremely common for some of the very first evaluators to look at transportation for whether a job is feasible to figure out whether someone can get there or notprimarily because we are talking about people who are looking for more entry level jobs in the local labor market and people know that they will have to get there at a particular shift. What is really challenging is what I just said about having to arrive at a certain time where there is not access through public transportation that will get you there or at the shift start time.

This statement about the process of screening clients for matching them with job opportunities reveals how transit dependency is seen as detrimental to a client's ability to reach certain jobs, and how service providers take transit dependent clients out of the running for such jobs without further assessing their fit. In other words, a workforce development professional's ability to do their job depends in no small part on their clients' access to transportation. In the case of a transit-dependent client, it is interdependent with transit planners' interest in providing mobility—as well as attracting ridership which will not materialize without the destination of a workplace to travel to.

Transit planners, as another example, understand disadvantaged workers' skill sets as a constraint on functionally serving marginalized populations even when transit does offer them convenient access to employment centers. The following quote from a planner with Metro Transit considers the problem in terms of historic shifts in employment patterns and downtown land use that make transit ridership dependent upon employees with certain skill sets: 
It was in Minneapolis, I mean there [was] all kinds of industry, [if] you look downtown at the buildings. It's all living places now, you used to [have] factories and business all located where all the transit went. Business [of that type] can't profit because it's so expensive downtown, so they go to the suburbs where it's cheaper, but the people aren't there.

This quote implies a belief that current downtown businesses (the easiest workplaces to serve with transit) do not provide jobs suitable for disadvantaged workers. Without the skills to obtain white collar, professional jobs, even transit planners understand disadvantaged workers as largely unable to benefit from high levels of downtown-focused transit service. This situation offers a strong reason for collaboration between transit planners and workforce development professionals, as neither can solve problems created by a lack of the other's services on their own.

This understood interdependency stands to reason-transit is used disproportionately by commuters and people without access to an automobile; if disadvantaged workers lack the skills they need to obtain jobs to commute to, transit use suffers. In addition, transit agencies have an important social equity mission in the form of providing the poor with access to opportunity-a mission it is unable to accomplish if spatial access to jobs is provided but job qualifications are lacking. The converse is equally true for workforce development agencies: excellent job qualifications with no means of reaching a workplace are of little functional benefit to clients.

\subsection{Authentic dialogue: Absences and opportunities}

In the DIAD model, authentic dialogue between stakeholders is crucial to moving from stakeholders' interests to collaborative action. Based on the interview results, the situation is much more mixed in terms of authentic dialogue than either diversity of interests or interdependence of interests. On a positive note, Washington County transit planners and workforce development professionals describe a standing, interagency group tasked specifically with creating dialogue around planning for the Gateway Corridor bus rapid transit line, as described here by one workforce development professional:

Well I'm I serve on the advisory commission. [...] Part of my role was to represent the low-income individuals from the workforce center in the corridor and it has a lot of people from the community all along that corridor like Oakdale, St. Paul, we have people who serve on the committee, so you get a voice from all these different folks, [...] the bottom line is it takes a long time for this process, you know from start to finish, you know, you're talking seven years before anything happens. But the collaboration really has been pretty good I think. Most of the cities and the counties are working really well together and a lot of the other community folks you know they see that something's got to happen because we can't continue to not have major transit running out here, I think the majority of the people know that. [...] So I think collaborating has really brought a lot of folks together that never would have talked.

The dialogue produced by this structure seems authentic in that it grows out of a mutual realization that the task of effectively connecting workers with jobs requires much more than a major transit investment made in a vacuum: the sheer magnitude of the problem posed by planning transit for a low-density, automobile-oriented, suburban landscape appears to lead to an understanding of the need for coordinated action. Other interviews paint a less optimistic picture, however. This appears to be less a problem of inauthentic dialogue than of a general lack of any direct dialogue between transit planners and workforce development professionals, despite their broadly shared understanding of interdependent interests. 
As an example: one of the most striking findings from comparing interviews with transit planners and workforce development professionals is that there is a strong, shared perception that greater collaboration would be beneficial to both types of work, but that it is not taking place. Despite this perception, however, participants engage in precious little consideration of how it might be accomplished. Given how important each group understands the results of other's work is to its own, this consistent absence appears at least as interesting as many concepts consistently present in the interviews. Further examination of transcripts suggests a surprisingly simple explanation: both groups see the problem, but without dialogue with the other, they lack the knowledge needed to craft actions to address it. The following quote from an interview with an executive with Metro Transit is illustrative of this gap:

We hear that transportation is an issue, and kind of what you're asking us is what part of transportation is the issue? Why is that? Well I don't know; we don't necessarily know either, so it would be interesting to hear [...] all these people who say transportation's an issue, what does it really mean? Is it that I just don't have the frequency of a bus route, or is it just too long a trip for me to make, or I got my kids I got to drop off on the way and how the hell do I do that while I'm on the bus with all my - I mean, what's the issue? We can't solve it unless we have some idea what that exact issue is!

\subsection{Additional collaboration themes: Regional transit development and suburban employer engagement}

Participants broadly share a perception that collaboration between transit planning and workforce development as a common practice is needed as the regional transit system continues to develop. This collaboration is perceived as particularly important in Brooklyn Park, North Minneapolis, Phillips, Golden Triangle, and Mall of America area. All these areas have premium transit service and/or significant planned transit improvements - in fact, current plans call for all of them to be connected with each other by light rail in the near future. On account of their different locations in the region and the roles they play in the regional economy, this collaboration would likely take different forms in different areas. For example, transit planning-workforce development collaboration in North Minneapolis might take the form of workforce centers focusing training and placement efforts on sectors and occupations common in areas which North Minneapolis residents have good transit access to, or will have good access to in the future. Transit planning-workforce development collaboration in the Golden Triangle area, on the other hand, might focus more on partnerships with employers focused on connecting them with disadvantaged workers who will have good access to Golden Triangle jobs once light rail opens.

Some examples of existing collaboration appear as well—such as between Metro Transit and a Brooklyn Park industrial park in extending a bus route to address labor supply problems. This example highlights possibilities and limitations of transit service to such employment centers: while the route attracted a base of ridership, first mile-last mile problems limit both the number of trips per day and ridership. The limited number of trips causes problems for workers lacking soft skills. For example, even a modest lack of punctuality can be dramatically magnified (and even lead to missing a day of work) if the worker in question depends on a bus route with long headways and limited service.

We worked a lot with Northland Industrial Park and the City of Brooklyn Park; they had a lot of entry-level mechanical and industrial positions and they had a hard time getting people to reliably come to work, and so we worked with them to extend a route from Brooklyn Park to Brooklyn Center right through their area, and worked with them on recruitment and training, and the biggest challenge [...] was getting enough people to make that trip that have the soft skills to keep the job. Sometimes it was "Im sorry I missed my bus", or "I lost my keys." Single trip options are really good for really organized people who plan on that one trip. 
In addition to developing a robust regional transit system, participants perceive the growing labor supply problem for outer suburban employers as an opportunity to engage such employers in future collaboration efforts. Both transit planners and workforce development professionals see a near-total lack of consideration of employee commutes or transit access in the location choice processes of major entry-level employers. Shakopee presents an extreme example of the workplace side of spatial mismatch, and the problems it creates for employers as well as workers: given limited affordable housing and large numbers of entry-level jobs, Shakopee employers would stand to benefit significantly from being able to recruit from areas such as Phillips and even North Minneapolis (to say nothing of benefits to workers from those areas). Distance and lack of transit options severely curtail that natural connection. These labor supply problems appear likely to worsen as new employers in the area open.

One example would be Valley Fair, and Mystic Lake casino and Canterbury Downs, they're actually all really interested in having better transit service, and they're in a place where there isn't that much. [...] So they're interested in working with the transit providers to provide that last mile connection, and not have us do it or have MVTA do it but, they're saying "Just get us to this point, we'll meet you at your transit center park and ride, and we'll take them the last $3 / 4$ mile."

\section{$5 \quad$ Conclusions and discussion}

Both transit planners and workforce development professionals lend support to the basic premise of this project: while successful collaboration between transit planning and workforce development is consistently acknowledged as beneficial, professionals in both fields perceive a need for more such collaboration. This perception is especially strong in suburban areas where transit has traditionally had less relevance to workforce development than in urban areas with at least high levels of traditional bus service. The perception is also exemplified by interviewees' wide-ranging discussion of affordable housing from an accessibility perspective, i.e., the need for considering the spatial distribution of affordable housing relative to both employment centers and the transit system. There is also a broad realization that workforce development efforts cannot simply give clients a bus card and send them on their way in suburban areas - even assuming future transit improvements. Urban areas suffer less from this issue on the home end of disadvantaged workers' commutes, but connecting urban workers with suburban jobs requires addressing the same issues at the workplace end, especially in terms of the first mile-last mile problem.

Our research also found that there was a broadly shared understanding of a need to consider both transit planning and workforce development more from the perspectives of individual riders and workers. Currently, workforce development efforts seek to address skills lacking in individual workers, without systematic consideration of their spatial context and concentrations; current transit planning largely considers only the spatial and most basic demographics of commute patterns, without direct information on individuals' skills or required qualifications for jobs. Disadvantaged workers can be better served by both fields by considering an individual's spatial context among their assets on the job market as well as by treating individuals and their skills as integral parts of their commutes. The heart of such a practice would be transit planners and workforce development professionals considering the following questions as an integrated, interconnected set:

- What skills do the people who live in an area have?

- What jobs are they willing to do?

- What jobs fitting people's skills and willingness can we provide training for?

- Which of those jobs can we connect people with via transit?

- Which employers in those occupations have diverse hiring practices?

- How can we interest those employers in hiring participating workers for those jobs? 
This unified system creates an aggregated, nuanced, and integrated understanding of labor supply and transit demand. It represents a broader approach to workforce development, by taking advantage of transit accessibility to reach the greatest feasible number of suitable job vacancies. It also represents a more individualized approach to transit planning: current predictions of transit demand depend heavily on basic demographics and general accessibility, without direct consideration of residents' qualifications or what specific jobs they can reach via transit.

Such an approach would absolutely depend on collaboration between a diverse group of actors as laid out in the DIAD model (Booher \& Innes, 2002; Innes \& Booher, 2010). Innes and Booher's (2010) concept of a "complex, adaptive system" which draws strength and adaptability from the diversity of its components and the complexity of their relationships is instructive, as it embraces the diverse nature of the actors involved in the proposed unified approach. What is crucial is to foster the authentic dialogue that the DIAD model depends on.

Transportation Management Organizations (TMOs) may offer one option for a convener of that dialogue. A convener can act as a focal point of collaborative planning processes and create a durable (or at least recurring) dialogic space to begin addressing them (Margerum, 2002). TMOs first arose as a response to highway congestion in the 1970s and 1980s, and have traditionally offered a variety of services such as coordinating carpools, establishing vanpools, advising commuters on using the transit system and/or advising employers on commute benefit programs (Ferguson, 2007). Given their focus on coordinating varied actors to expand transportation options in specific, sub-regional geographic areas, TMOs are natural allies in advancing coordinated transit planning and workforce development efforts. There are currently four TMOs operating in both central cities and two major suburban employment areas in the Twin Cities region, and similar organizations are common in other regions as well. The TMO structure of working with a variety of stakeholders united by a geographic location may allow for the coordination of transportation demand to the point of justifying medium-intensity transportation services such as community bus- or van-based shuttles.

While local organizations such as TMOs may offer important points of collaboration in connecting workers and employers with transit, the sheer size of the first mile/last mile problem calls for a further diversity of solutions. In the Twin Cities region, and in other regions as well, there are many employment centers where providing high quality, fixed-route bus services is simply impossible due to low densities, circuitous street networks, and poor pedestrian environments. While bus connections are critical to the success of major transit projects, connecting disadvantaged workers with many suburban workplaces near LRT or BRT stations but outside their walking distance will require additional options. These options could potentially include employer or district shuttles, car and/or bicycle sharing, or partnerships with transportation networking companies, such as Lyft or Uber. While making many of these options available to the working poor would likely require public subsidies, those subsidies could potentially be much less per rider than traditional demand-responsive transit service. Much as user owned automobiles and park-and-ride facilities ease the challenge of connecting suburban workers with urban jobs by transit, some combination of demand-responsive services and/or shared use mobility may similarly ease the challenge of connecting urban residents with suburban jobs by transit. Given persistent patterns of urban and inner-suburban intergenerational poverty as well as job suburbanization, this inversion of the traditional park-and-ride model could allow suburban transit investments to serve as powerful social equity promoters.

It will also be crucial to consider the specific spatial and schedule patterns of high-demand sectors in planning first mile/last mile service. More dispersed sectors may need a larger number of smaller vehicles with more route flexibility, while more concentrated sectors may be well served with somewhat larger vehicles and more regular routings. 
In closing, great challenges remain in the way of addressing spatial and skills mismatch issues in the Twin Cities region. However, the present is a uniquely opportune time to lay the groundwork for a new, coordinated approach to addressing these issues. Implementing any of the specific policy recommendations above will require collaboration between agencies and organizations with highly diverse interests. The interdependence of those interests, however, along with the magnitude of the public investments and planning efforts surrounding the buildout of the regional transitway system mean that transit is on the minds of planners, workforce development professionals, elected officials, employers and other stakeholders throughout the region. These groups see transit investments as opportunities for transformative change. What's more, there is at least an implicit understanding that transformative change is needed if these major public investments are to succeed. This understanding offers the potential to create the authentic dialogue required for fully-realized collaborative rationality in coordinating transit planning and workforce development in the region. Transit corridors hold great potential to serve as leverage points to bring diverse stakeholder groups to the table, and the acceleration of the regional transit system buildout calls for making such contacts sooner rather than later.

\section{Acknowledgements}

The research is jointly funded by the McKnight Foundation, the Hennepin County, and the Jay and Rose Phillips Family Foundation. The authors wish to offer their sincere thanks to the members of the national advisory panel convened for this research project for their expert guidance in performing the research. The project advisors include Eric Muschler, McKnight Foundation; Scott Bernstein, Center for Neighborhood Technology; Oriane Casale, Minnesota Department of Employment and Economic Development; Mike Christenson, Minneapolis Community and Technical College; John Doan, Hennepin County; Faith Hall, Federal Transit Administration; Greg LeRoy, Good Jobs First; Bryan Lindsley, MSP Workforce Innovation Network; Joel Luedtke, Jay and Rose Phillips Family Foundation; Laurie McGinnis, University of Minnesota; Jodi Sandfort, University of Minnesota; Ben Seigel, U.S. Department of Labor; Dane Smith, Growth and Justice; and Mariia Zimmerman, MZ Strategies, LLC. 


\section{References}

Bauder, H., \& Perle, E. (1999). Spatial and skills mismatch for labor-market segments. Environment and Planning A, 31(6), 959-977.

Blumenberg, E., \& Manville, M. (2004). Beyond the spatial mismatch: Welfare recipients and transportation policy. Journal of Planning Literature, 19(2), 182-205.

Booher, D., \& Innes, J. (2002). Network power in collaborative planning. Journal of Planning Education and Research, 21(3), 221-236.

Chapple, K. (2006). Overcoming mismatch: Beyond dispersal, mobility, and development strategies. Journal of the American Planning Association, 72(3), 322-336.

Chapple, K. (2009). Mapping susceptibility to gentrification: The early warning toolkit. Berkeley, CA: Center for Community Innovation, University of California.

Chetty, R., Hendren, N., Kline, P., \& Saez, E. (2014). Where is the land of opportunity? The geography of intergenerational mobility in the United States. The Quarterly Journal of Economics, 129(4), 1553-1623.

Corak, M. (2013). Income inequality, equality of opportunity, and intergenerational mobility. The Journal of Economic Perspectives, 27(3), 79-102.

Department of Employment and Economic Development. (2016). Job vacancy survey. Saint Paul, MN: Minnesota Department of Employment and Economic Development.

District Councils Collaborative. (2014). Corridors 2 careers: Building work-ready communities. Retrieved from http://dcc-stpaul-mpls.org/special-projects/C2C

Elman, C. (2005). Explanatory typologies in qualitative studies of international politics. International Organization, 59(2), 293-326. Retrieved from http://www.jstor.org.ezp3.lib.umn.edu/stable/3877906

Fan, Y., Guthrie, A., \& Levinson, D. (2012). Impact of light-rail implementation on labor market accessibility: A transportation equity perspective. Journal of Transport and Land use, 5(3), 28-39.

Fan, Y. (2012). The planners' war against spatial mismatch lessons learned and ways forward. Journal of Planning Literature, 27(2), 153-169.

Ferguson, E. (2007). Transportation management associations: A reappraisal. Journal of Public Transportation, $10(4), 1$.

Giloth, R. (2000). Learning from the field: Economic growth and workforce development in the 1990s. Economic Development Quarterly, 14(4), 340-359.

Gobillon, L., Selod, H., \& Zenou, Y. (2007). The mechanisms of spatial mismatch. Urban Studies, 44(12), 2401-2427.

Grengs, J. (2010). Job accessibility and the modal mismatch in Detroit. Journal of Transport Geography, $18(1), 42-54$.

Handel, M. J. (2003). Skills mismatch in the labor market. Annual Review of Sociology, 29, 135-165.

Haughton, G. (1990). Skills mismatch and policy response. Policy \& Politics, 18(4), 279-287.

Houston, D. (2005). Employability, skills mismatch and spatial mismatch in metropolitan labor markets. Urban Studies, 42(2), 221-243.

Immergluck, D. (1998). Job proximity and the urban employment problem: Do suitable nearby jobs improve neighborhood employment rates? Urban Studies, 35(1), 7-23.

Innes, J., \& Booher, D. (2010). Planning with complexity: An introduction to collaborative rationality for public policy. New York: Routledge.

Kain, J. (1968). Housing segregation, Negro employment, and metropolitan decentralization. Quarterly Journal of Economics, 82(2), 175-197.

Kasarda, J. (1990). The jobs-skills mismatch. New Perspectives Quarterly, 7(4), 34-37. 
Margerum, R. (2002). Collaborative planning: Building consensus and building a distinct model for practice. Journal of Planning Education and Research, 21(3), 237-253.

McQuaid, R. (2006). Job search success and employability in local labor markets. The Annals of Regional Science, 40(2), 407-421.

Mile High Connects. (2016). Mile high connects: Opportunity for all through transit. Retrieved from http://milehighconnects.org/main.html

O’Niel, T. (2016). Addressing a tighter labor market. Saint Paul, MN: Minnesota Department of Employment and Economic Development.

Skinner, C. (2001). Measuring skills mismatch New York City in the 1980s. Urban Affairs Review, 36(5), 678-695.

Stoll, M. (2005). Geographical skills mismatch, job search and race. Urban Studies, 42(4), 695-717.

Turner, M., Edelman, P., Poethig, E., \& Aron, L. (2014). Tackling persistent poverty in distressed urban neighborhoods. (White paper). Washington, DC: Urban Institute.

U.S. Census Bureau. (2016a). Per-capita income in the past 12 months (in 2014 inflation-adjusted dollars) (black or African American alone). Retrieved from http://factfinder.census.gov/faces/tableservices/jsf/pages/productview.xhtml?pid=ACS_14_5YR_B19301B\&prodType=table

U.S. Census Bureau. (2016b). Per-capita income in the past 12 months (in 2014 inflation-adjusted dollars) (white alone, not Hispanic or Latino). Retrieved from http://factfinder.census.gov/faces/ tableservices/jsf/pages/productview.xhtml?pid=ACS_14_5YR_B19301H\&prodType=table 